Jurnal Kebidanan 10 (01) 1 - 102

Jurnal Kebidanan

http : //www. journal.stikeseub.ac.id

\title{
EFEKTIVITAS KELAS IBU HAMIL TERHADAP PENINGKATAN PENGETAHUAN TENTANG BUKU KIA
}

\author{
Titik Wijayanti ${ }^{1)}$, Atik Setiyaningsih ${ }^{2)}$ \\ ${ }^{1), 2)}$ Prodi D3 Kebidanan STIKES Estu Utomo Boyolali \\ E-mail : titikeub.tw@gmail.com,dosenmanis@yahoo.com
}

\begin{abstract}
ABSTRAK
Tingginya Angka Kematian Ibu (AKI) di Boyolali terlihat dari data tahun 2014 sebesar 93,05/100.000 kelahiran hidup. Penyebab kasus kematian di Boyolali tersebut karena ekalmsi, perdarahan, infeksi dan lain-lain. (Dinkes Kab. Boyolali, 2014). Kematian ibu dapat dicegah apabila dapat dilaksanakan penanganan secara cepat dan tepat. Penanganan cepat dapat dilakukan apabila penyakit dapat dideteksi secara dini. Pengetahuan tentang deteksi dini dapat diperoleh melalui kelas ibu hamil di tingkat desa yang merupakan program dari pemerintah yang dicanangkan sejak tahun 2009. Salah satu media yang digunakan pada saat kelas ibu hamil adalah buku KIA. Di dalam buku KIA terdapat berbagai informasi tentang kesehatan ibu dan anak termasuk deteksi dini komplikasi/ penyulit. Penelitian ini merupakan penelitian quasi experiment dengan rancangan One group pretest-posttest, dimana kelompok ibu hamil diberikan pre test terlebih dahulu, kemudian diberikan perlakukan kelas ibu hamil 4x pertemuan dan diakhiri dengan post test. Populasi sejumlah 31 orang ibu hamil dengan responden 30 ibu hamil, diambil dengan tehnik purposive sampling. Penelitian dilakukan di desa Kragilan, Mojosongo, Boyolali. Analisis data menggunakan paired t test. Hasil penelitian menunjukan pada saat pre test, responden yang memiliki pengetahuan tentang Buku KIA pada kategori baik $(76 \%-100 \%)$ sebanyak 3 responden (10\%), dan pada saat post test, pengetahuan responden tentang buku KIA pada kategori baik mengalami peningkatan menjadi 20 responden $(66,7 \%)$. Hasil analisis data menunjukkan nilai $\rho$ value $(0,00)<\alpha(0,05)$ yang artinya kelas ibu hamil efektif meningkatkan pengetahuan tentang Buku KIA. Nilai corelation 0,856 menunjukkan bahwa kelas ibu hamil memiliki pengaruh yang erat terhadap peningkatan pengetahuan tentang Buku KIA.
\end{abstract}

Kata kunci : kelas ibu hamil, pengetahuan tentang buku KIA

\section{EFFECTIVENESS OF PREGNANT WOMEN CLASS ON IMPROVEMENT KNOWLEDGE ABOUT KIA BOOK \\ ABSTRACT}

The high maternal mortality rate (MMR) in Boyolali is seen from 2014 data of 93.05 / 100,000 live births. The cause of death cases in Boyolali is due to ekalmsi, bleeding, infection and others. (Health Office Boyolali District, 2014). Maternal death can be prevented if handling can be done quickly and accurately. Fast treatment can be done if the disease can be detected early. Knowledge of early detection can be obtained through pregnant women's classes at the village level which is a government program proclaimed since 2009. One of the media used during the pregnant mother's class is the KIA book. In KIA books there are various information about maternal and child health including early detection of complications / complications. This research is a quasi experiment research with One group pretest-posttest design, where group of pregnant mother is given pre test first, then given treatment class of $4 x$ pregnant woman meeting and ending with post test. The population of 31 pregnant women with respondents 30 pregnant women, taken with purposive sampling technique. The study was conducted in the village of Kragilan, Mojosongo, Boyolali. Data analysis using paired test. The result of the research shows that in the pre test, respondents who have knowledge about KIA Book in good category (76\% $100 \%)$ are 3 respondents (10\%), and at post test, the knowledge of respondents about KIA book in good category has increased to become 20 respondents (66.7\%). The result of data analysis shows the value of $\rho$-value $(0,00)<\alpha(0,05)$, which means the maternal class is effective to increase the knowledge of KIA Book. The value of corelation 0.856 indicates that the class of pregnant women has a close influence on the increased knowledge of the KIA Book.

Keywords: class of pregnant mother, knowledge of KIA book 


\section{PENDAHULUAN}

Program pembangunan kesehatan di Indonesia dewasa ini masih diprioritaskan pada upaya peningkatan derajad kesehatan ibu dan anak, terutama pada kelompok yang paling rentan kesehatan yaitu ibu hamil, bersalin, nifas dan bayi pada masa perinatal. Hal ini ditandai dengan tingginya Angka Kematian Ibu (AKI) dan Angka Kematian Bayi (AKB). (Kemenkes RI, 2011). Angka Kematian Ibu (AKI) di Indonesia tahun 2014 sebesar 359/100.000 kelahiran hidup dan kematian bayi sebesar 32/1000 kelahiran hidup (SDKI 2012). Sedangkan di Jawa Tengah AKI sebanyak 126,55/100.000 KH dan AKI di Boyolali sebesar 93,03/100.000 KH (Dinkes Prop Jateng, 2014).

Tingginya Angka Kematian Ibu (AKI) tersebut disebabkan karena faktor penyebab langsung dan tidak langsung. Di mana penyebab langsung diantaranya hipertensi, perdarahan, infeksi,gangguan sistem peredaran darah dan lain - lain. Hal ini bisa dicegah dengan melakukan deteksi dini resiko tinggi kehamilan. Sedangkan penyebab tidak langsung diantaranya karena penyakit yang diderita ibu yang dapat memperberat kehamilan, termasuk kemiskinan, pendidikan yang rendah serta keadaan sosial budaya. Pendidikan ibu hamil dan keluarga yang rendah secara tidak langsung akan mempengaruhi pengetahuan tentang segala sesuatu yang berhubungan dengan kehamilan, sehingga akan berpengaruh juga terhadap pola pikir ibu hamil dalam melakukan perawatan kehamilan maupun pengambilan keputusan apabila timbul tanda bahaya kehamilan ataupun komplikasi kehamilan. (Savitri, T, 2012).

$$
\text { Masih tingginya Angka }
$$

Kematian Ibu di Boyolali diantaranya disebabkan karena kurangnya pengetahuan ibu hamil tentang tanda bahaya kehamilan sehingga ibu hamil datang ke tenaga kesehatan dengan komplikasi kehamilan yang tidak diketahui sebelumnya, juga karena faktor gizi maupun ekonomi.(Profil Kesehatan Kab. Boyolali, 2014).

Salah satu upaya yang dilakukan pemerintah dalam rangka menurunkan Angka Kematian Ibu (AKI) dan Angka Kematian Bayi (AKB) adalah program kelas ibu hamil. Dimana dengan kelas ibu hamil merupakan saran untuk belajar bersama tentang kesehatan ibu hamil dalam bentuk tatap muka dalam kelompok yang bertujuan untuk meningkatkan pengetahuan dan ketrampilan ibu mengenai kehamilan, perawatan kehamilan, persalinan, perawatan nifas, perawatan bayi baru lahir, mitos, penyakit menular dan akte kelahiran. Dengan meningkatnya 
pengetahuan dan ketrampilan ibu hamil, maka ibu hamil akan dapat mengidentifikasi sedini mungkin apabila terjadi kondisi yang tidak normal melalui pemanfaatan Buku KIA untuk selanjutnya segera menuju fasilitas pelayanan kesehatan agar mendapat penanganan segera sehingga komplikasi baik pada ibu dan bayi dapat ditangani dengan baik yang akan berdampak pada penurunan AKI dan AKB. (Kemenkes RI, 2011).

Di wilayah kabupaten Boyolali, masih ada beberapa desa yang belum melaksanakan kelas ibu hamil. Diantaranya desa Kragilan, kecamatan Mojosongo, kabupaten Boyolali, untuk itu penulis tertarik untuk melaksanakan kelas ibu hamil di desa tersebut bekerjasama dengan bidan desa, kemudian dievaluasi efektifitasnya terhadap peningkatan pengetahuan tentang buku KIA.

Pengetahuan adalah merupakan hasil dari tahu dan ini terjadi setelah orang melakukan pengindraan terhadap obyek tertentu. Pengetahuan tercakup dalam domain kognitif yang terdiri dari tahu, memahami, aplikasi, analisis, sintesis dan evaluasi. Ada beberapa faktor yang mempengaruhi pengetahuan seseorang yaitu tingkat pendidikan, informasi, pengalaman, budaya dan sosial ekonomi. (Notoatmodjo,S; 2007).
Buku KIA adalah buku catatan terpadu yang digunakan dalam keluarga dan masyarakat dalam memelihara / merawat kesehatan ibu dan anak, serta meningkatkan kualitas pelayanan KIA. Buku KIA merupakan buku yang berisi catatan kesehatan ibu (hamil, bersalin dan nifas termasuk KB) serta catatan kesehatan anak (bayi baru lahir sampai 6 tahun) serta berbagai informasi cara memeliharan dan merawat kesehatan ibu dan anak.( Buku KIA, 2016).

Kelas ibu hamil adalah kelompok belajar ibu-ibu hamil dengan umur kehamilan antara $4-36$ minggu (menjelang persalinan) dengan jumlah peserta maksimal 10 orang. Adapun tujuan kelas ibu hamil adalah meningkatkan pengetahuan, merubah sikap dan perilaku ibu agar memahami tentang Kehamilan, perubahan tubuh dan keluhan selama kehamilan, perawatan kehamilan, persalinan, perawatan Nifas, KB pasca persalinan, perawatan bayi baru lahir, mitos/kepercayaan/adat istiadat setempat, penyakit menular dan akte kelahiran. Pertemuan kelas ibu hamil dilakukan 4 kali pertemuan selama hamil atau sesuai dengan hasil kesepakatan fasilitator dengan peserta. Pada setiap pertemuan, materi kelas ibu hamil yang akan disampaikan disesuaikan dengan kebutuhan dan kondisi ibu hamil tetapi tetap mengutamakan materi pokok. Pada setiap 
akhir pertemuan dilakukan senam ibu hamil. Senam ibu hamil merupakan kegiatan/materi ekstra di kelas ibu hamil, jika dilaksanakan, setelah sampai di rumah diharapkan dapat dipraktekkan. (Kemenkes RI, 2011).

Dengan pengetahuan yang baik tentang masa kehamilan, persalinan, nifas dan bbl maka seorang ibu akan dapat melakukan perawatan serta deteksi dini tanda bahaya ataupun resiko tinggi secara mandiri yang dapat membantu menurukan angka kematian ibu dan bayi di kabupaten Boyolali, karena tidak ada lagi keterlambatan dalam melakukan deteksi dini, pengambilan keputusan dan keterlambatan dalam merujuk. Dari segi ilmu pengetahuan, hasil penelitian ini dapat menambah wawasan dan informasi tentang buku KIA kepada ibu hamil.

\section{METODE}

Penelitian yang digunakan adalah penelitian eksperimen semu atau quasi experiment designs, dengan rancangan one group pretest-postest. Dimana dalam penelitian ini akan dilakukan pretest sebelum diberikan perlakuan serta akan dilakukan posttest setelah diberikan perlakuan. (Notoatmodjo, 2005). Perlakuan disini adalah pelaksanaan kelas ibu hamil 4x pertemuan. Penelitian ini diawali dengan survey pendahuluan untuk menggali masalah, uji coba instrumen (kuesioner) dengan uji validitas dan reliabilitas, pelaksanaan penelitian meliputi penilaian awal (pretest), dilanjutkan pelaksanaan kelas ibu hamil sebanyak $4 \times$ atau sesuai kesepakatan dengan peserta dan diakhiri dengan penilaian akhir (posttest), dilanjutkan tabulasi dan pengolahan data. Penelitian ini dilaksanakan di desa Kragilan, Kecamatan Mojosongo, Kabupaten Boyolali dari bulan Maret Juni 2014.

Populasi dalam penelitian ini adalah seluruh ibu hamil di wilayah desa Kragilan, Mojosongo, Boyolali sejumlah 31 ibu hamil. Teknik sampling yang digunakan adalah purposive sampling dengan kriteria inklusinya ibu hamil yang bersedia menjadi responden, hadir pada saat pre test dan mengikuti kelas hamil 4 kali pertemuan, sehingga sampel yang digunakan adalah sebagian ibu hamil di desa Kragilan, Kecamatan Mojosongo, Kabupaten Boyolali yang memenuhi kriteria inklusi sejumlah 30 ibu hamil.

Alat yang digunakan untuk pengumpulan data varibale kelas ibu hamil adalah daftar hadir peserta dan buku KIA, sedangkan untuk variabel pengetahuan tentang buku KIA adalah kuesioner. Data yang digunakan ada data primer baik untuk variabel kelas hamil maupun pengetahuan tentang buku KIA, kemudian data sekunder diperlukan untuk mengetahui jumlah ibu hamil di desa Kragilan, 
kecamatan Mojosongo, kabupaten Boyolali.

Uji coba instrumen dilakukan terhadap 30 responden ibu hamil di desa Gagaksipat, Ngemplak, Boyolali meliputi uji validitas dianalisis dengan rumus Product Moment didapatkan hasil $\mathrm{R}>\mathrm{r}$ tab yaitu $0,650>0,361$ artinya kuesioner yang digunakan valid/ sahih. Sedangkan untuk uji realibilitas dianalisis menggunakan rumus Alpha Chronbach didapatkan hasil $r 1>r$ tab yaitu 0,761> 0,361 artinya kueisoner yang digunakan reliabel/ konsisten.

Setelah semua data terkumpul, data tersebut kemudian dilakukan analisis data dengan menggunakan paired $t$ test (Riwidigdo, $\mathrm{H}$; 2008).

\section{HASIL DAN PEMBAHASAN}

\section{Hasil Penelitian}

\section{Analisis Univariat}

Distribusi frekuensi Pengetahuan Ibu Hamil Tentang Buku KIA pre dan post test dapat di lihat pada tabel di bawah ini.

Tabel 1. Distribusi Frekuensi Hasil Pre-Post Test Pengetahuan Ibu Hamil Tentang Buku KIA

\begin{tabular}{ccccc}
\hline $\begin{array}{c}\text { Pengetahuan tentang } \\
\text { Buku KIA }\end{array}$ & Frekuensi & $\begin{array}{c}\text { Pre Test } \\
\text { Prosentase } \\
(\%)\end{array}$ & Frekuensi & $\begin{array}{c}\text { Prosentase } \\
(\%)\end{array}$ \\
\hline Baik $(75 \%-100 \%)$ & 3 & 10,0 & 20 & 66,67 \\
Cukup $(56 \%-75 \%)$ & 15 & 50,0 & 9 & 30,0 \\
Kurang $(\leq 55 \%)$ & 12 & 40,0 & 1 & 3,33 \\
\hline Total & $\mathbf{3 0}$ & $\mathbf{1 0 0 , 0}$ & $\mathbf{3 0}$ & $\mathbf{1 0 0 , 0}$ \\
\hline
\end{tabular}

Sumber : Data Primer di olah, 2014

Berdasarkan tabel 1 di atas menunjukkan bahwa pada saat pre test pengetahuan ibu hamil tentang buku KIA mayoritas berada pada kategori cukup sebanyak 15 responden $(50 \%)$ serta kategori baik hanya sebanyak 3 responden (10\%). Sedangkan pengetahuan ibu hamil tentang buku KIA pada saat post test mayoritas berada pada kategori baik sebanyak
20 responden $(66,67 \%)$, serta kategori kurang hanya 1 responden $(3,3 \%)$. Pengetahuan ibu hamil saat post test yang dalam kategori baik mengalami kenaikan 56,67 \%, sedangkan pengetahuan kategori cukup menurun sebanyak $20 \%$ serta pengetahuan kategori kurang juga mengalami penurunan sebanyak $36,67 \%$. 


\section{Analisis Bivariat}

Hasil uji statistik efektifitas kelas ibu hamil terhadap Pengetahuan Ibu Hamil Tentang Buku KIA, dapat di lihat pada tabel di bawah ini.

Tabel 2. Efektifitas Kelas Ibu Hamil terhadap Pengetahuan Ibu Hamil Tentang Buku KIA

\begin{tabular}{ccccccccc}
\hline \multirow{2}{*}{ Deteksi Dini } & \multicolumn{3}{c}{ Pre Test } & \multicolumn{2}{c}{ Post Test } & & $\begin{array}{c}\text { Corre } \\
\text { lation }\end{array}$ & $\begin{array}{c}\boldsymbol{\rho}- \\
\text { value }\end{array}$ \\
\hline Baik $(75 \%-100 \%)$ & 3 & 10,0 & 5,733 & 20 & 66,67 & 9,193 & 0,856 & 0,00 \\
Cukup $(56 \%-75 \%)$ & 15 & 50,0 & & 9 & 30,0 & & & \\
Kurang $(\leq 55 \%)$ & 12 & 40,0 & & 1 & 3,33 & & & \\
Total & $\mathbf{3 0}$ & $\mathbf{1 0 0 , 0}$ & & $\mathbf{3 0}$ & $\mathbf{1 0 0 , 0}$ & & & \\
\hline
\end{tabular}

Sumber : Data Primer di olah, 2014

Hasil analisis data dengan uji paired $t$ test pada tabel 2 diatas menunjukkan terjadi peningkatan nilai rata-rata pre test dan post test sebesar 3,46 dan nilai $\rho$-value $(0,00)<\alpha(0,05)$ yang artinya kelas ibu hamil efektif meningkatkan pengetahuan tentang buku KIA. Nilai korelasi 0, 856 menunjukkan bahwa kelas ibu hamil berkaitan sangat erat terhadap peningkatan pengetahuan tentang buku KIA.

\section{Pembahasan}

\section{Pengetahuan Ibu Sebelum Mengikuti}

Kelas Ibu Hamil

Berdasarkan hasil pre test diketahui bahwa pengetahuan responden tentang buku KIA masih kurang, dibuktikan dari 30 respoden hanya 3 responden (10\%) yang memiliki pengetahuan baik dalam deteksi dini tanda bahaya kehamilan, pengetahuan cukup 15 responden 50\%) dan pengetahuan kurang 12 responden (40\%). Hal ini dipengaruhi oleh berbagai faktor, diantaranya pendidikan, informasi dan pengalaman (Notoatmodjo, 2007). Tingkat pendidikan seseorang akan mempengaruhi pola pikir sikap dan perilaku dalam hal ini akan meningkatkan pengetahuan responden tentang buku KIA, berdasarkan hasil penelitian pendidikan responden mayoritas menengah (14 responden/ $46,7 \%)$. Seseorang yang memiliki banyak sumber informasi akan mempunyai pengetahuan yang luas, berdasarkan hasil penelitian responden belum mendapatkan informasi yang detail tentang buku KIA sehingga pengetahuannya masih kurang. Pengalaman merupakan sesuatu yang pernah dialami seseorang akan menambah pengetahuan tentang sesuatu yang bersifat informal dalam hal iniadalah paritas, responden sejumlah 15 (50\%) merupakan primipara sehingga belum pernah mendapatkan pengalaman dari kehamilan sebelumnya sehingga pengetahuan masih terbatas. 
Pengetahuan Ibu Setelah Mengikuti Kelas Ibu Hamil

Berdasarkan hasil post test diketahui bahwa pengetahuan responden tentang buku KIA mayoritas dalam kategori baik, hal ini dibuktikan dari 30 responden sebanyak 20 responden $(66,67 \%)$ memiliki pengetahuan baik tentang buku KIA, pengetahuan cukup sebanyak 9 responden (30\%), serta pengetahuan kurang sebanyak 1 responden (3,3\%). Hal ini selain dipengaruhi oleh faktor pendidikan, dan pengalaman yang tidak kalah penting adalah informasi yang sudah diberikan dalam bentuk kelas ibu hamil , bahwa dengan memberikan informasi sebanyak - banyaknya dengan metode yang tepat akan dapat meningkatkan pengetahuan responden. (Notoatmodjo, 2007). Pemberian informasi dalam bentuk kelas ibu hamil dilakukan sebanyak 4 kali pertemuan dengan menggunakan materi yang ada di buku KIA sehingga akan meningkatkan pengetahuan ibu hamil tentang isi buku KIA. (Kemenkes RI, 2011).

\section{Efektifitas Kelas Ibu Hamil Terhadap} Peningkatan Pengetahuan Tentang

\section{Buku KIA}

Berdasarkan hasil analisis data dengan paired t test menunjukkan nilai $\rho$ value $(0,00)<\alpha(0,05)$ yang artinya kelas ibu hamil efektif meningkatkan pengetahuan ibu hamil tentang buku
KIA. Nilai corelation 0,856 menunjukkan bahwa kelas ibu hamil memiliki pengaruh yang erat terhadap pengetahuan ibu hamil tentang buku KIA.. Hal ini sesuai teori Kemenkes RI, 2011 yang menyatakan bahwa dengan pemberian informasi dalam bentuk kelas ibu hamil dilakukan sebanyak 4 kali pertemuan dengan menggunakan materi yang ada di buku KIA sehingga akan meningkatkan pengetahuan ibu hamil tentang isi buku KIA. Dengan kelas ibu hamil, akan meningkatkan interaksi antar ibu hamil dengan ibu hamil dimana mereka akan berbagi pengalaman seputar kehamilan , juga meningkatkan interaksi antara ibu hamil dengan bidan/ petugas kesehatan tentang kehamilan, persalinan, masa nifas, KB, BBL sampai anak usai 6 tahun. Dengan demikian pemahaman dan pengetahuan tentang buku KIA akan mengalami peningkatan. (Kemenkes RI, 2011).

\section{PENUTUP}

Berdasarkan hasil dan pembahasan diatas, maka dapat disimpulkan bahwa pengetahuan ibu hamil tentang buku KIA sebelum mengikuti kelas hamil mayoritas dalam kategori cukup 15 responden (50\%), kurang 12 responden (40\%) dan baik 3 responden (10\%), sedangkan pengetahuan ibu hamil tentang buku KIA setelah mengikuti kelas hamil sebagian besar dalam kategori baik 20 responden 
(66,67\%), cukup 9 responden (30\%) serta kurang 1 responden $(3,3 \%)$ serta kelas ibu hamil efektif meningkatkan pengetahuan ibu hamil tentang buku KIA (nilai $\rho$-value $(0,00)<\alpha(0,05))$ dengan korelasi yang erat $(0,856)$.

Berdasarkan kesimpulan tersebut saran yang dapat diberikan antara lain meneruskan kegiatan kelas ibu hamil yang sudah dirintis, meningkatkan partisipasi kader kesehatan dalam pelaksanaan kelas ibu hamil serta melakukan kerjasama/ koordinasi dengan Puskesmas dan Dinas Kesehatan Kabupaten guna keberlangsungan kelas ibu hamil.

\section{DAFTAR PUSTAKA}

Anomin, 2010. Buku Kesehatan Ibu dan Anak. Kemenkes RI, Jakarta.

Anonim; 2011. Pedoman Pelaksanaan Kelas Ibu Hamil, Kemenkes RI, Jakarta.

Anonim; 2012. Survey Kesehatan Demografi Indonesia (SDKI) 2012 " Laporan Pendahuluan". BPS, BKKN, Kemenkes RI, Jakarta.

Anonim, 2014. Profil Kesehatan Propinsi Jawa Tengah Tahun 2014. Dinkes Prop. Jateng.

Anonim, 2014. Profil Kesehatan Kabupaten Boyolali Tahun 2014. Dinkes Kab. Boyolali

Anonim, 2016. Buku Kesehatan Ibu dan Anak. Kemenkes RI, Jakarta

Arikunto, S; 2006. Prosedur Penelitian Suatu Pendekatan Praktek. Rineka Cipta Jakarta..

Notoatmodjo, S; 2005. Metode Penelitian Kesehatan. Rineka Cipta, Jakarta.

Notoatmodjo, S; 2007. Ilmu Kesehatan Masyarakat. Rineka Cipta, Jakarta

Notoatmojo, S:2007. Promosi Kesehatan dan Ilmu Perilaku. Rineka Cipta, Jakarta

Riwidikdo, H; 2008. Statistika Terapan dengan Program $R$ Versi 2.5.1. Mitra Cendikia, Yogyakarta.

Savitri, T; 2012. Penyebab Utama Angka Kematian Ibu di Indonesia. www.majalahkesehatan.com. Diakses tanggal 1 Desember 2013. 